\title{
Investigation of Fracture Surfaces of Soft Magnetic Materials
}

\author{
J. Bidulská ${ }^{a, *}$, T. KvaČKaj ${ }^{a}$, R. Bidulskŕ ${ }^{b}$, M. ACtis Grande ${ }^{b}$ And L. Ferraris ${ }^{b}$ \\ ${ }^{a}$ Technical University of Košice, Faculty of Metallurgy, Letná 9, 04200 Košice, Slovakia \\ ${ }^{b}$ Politecnico di Torino-Alessandria Campus, V. Teresa Michel 5, 15100 Alessandria, Italy
}

\begin{abstract}
The present paper focused on the analysis of the fracture surfaces of a new development insulated iron powder compound with the addition of the aluminium alloy in order to improve the mechanical properties. Results show that in the pressed state, mainly pores act as crack initiators and due to their presence the distribution of stress is inhomogeneous across the cross-section and leads to the reduction of the effective load bearing area. Investigation of fracture surfaces concluded that improvements in bonding during the pressing process and heat treatment can be helpful in the development of soft magnetic materials to give a suitable combination between pressing pressure, annealing temperature and time as well as magnetic properties.
\end{abstract}

PACS numbers: 75.50.-y, 81.20.Ev, 81.40.Np

\section{Introduction}

The powder metallurgy (PM), and in particular the possibility to manufacture net shape parts, can significantly modify the way of projecting several devices or parts regarding magnetic circuits. One of the electromagnetic applications is powder core, which uses iron powder dispersed in a plastic or polymer compacted to different shapes $[1,2]$. These cores provide a constant permeability over wide range of frequencies. Iron powder cores are the lowest cost alternatives to ferrites but can provide a higher induction compared to soft ferrites. The applications include switch mode power supplies and other high frequency broadband applications [3].

Powder cores use iron powder dispersed in a plastic or polymer compacted to different shapes.

The effect of the processing parameters on the magnetic properties achievable by soft magnetic materials (SMM) has already been evaluated elsewhere [1-6]. It was concluded that improvements in bonding during the pressing process and heat treatment can be helpful in the development of SMM to give a suitable combination between pressing pressure, annealing temperature and time as well as magnetic properties.

The main aim of the present work was the analysis of the fracture surfaces of an insulated iron powder compacts (IIPC) with addition of the aluminium alloy in order to improve the mechanical properties without losing the positive magnetic characteristics.

\section{Experimental procedures}

The starting material was IIPC with an addition of $5 \mathrm{wt} \%$ aluminium alloy (Al- $0.95 \mathrm{wt} \% \mathrm{Mg}-0.49 \mathrm{wt} \% \mathrm{Si}-$ $0.21 \mathrm{wt} \% \mathrm{Cu}-0.07 \mathrm{wt} \% \mathrm{Fe}$ ). The aluminium alloy was added to the starting material in terms of the better mechanical properties and specimen can be shaped easily during pressing process.

\footnotetext{
* corresponding author; e-mail: jana.bidulska@tuke.sk
}

Particles size distribution was carried out by sieve analyzer according to ISO 4497. Powder mixtures were homogenized using a laboratory Turbula mixer for $1200 \mathrm{~s}^{-1}$. Specimens with a different green density were obtained using a $2000 \mathrm{kN}$ hydraulic press, in a disc-shaped mould $\left(\varnothing 40 \times 10^{-3} \mathrm{~m}\right)$ and unnotched impact energy $(55 \times 10 \times$ 10) $\times 10^{-3} \mathrm{~m}^{3}$ specimens, applying a pressure in the range from 400 to $800 \mathrm{MPa}$. Heat treatment was carried out in vacuum furnace at $773 \mathrm{~K}$ for $1800 \mathrm{~s}^{-1}$. Densities were evaluated using the water displacement method.

\section{Results and discussion}

The evaluation of particle size distribution revealed that the largest fraction (50.97\%) of particles for the investigated material is in range of 63 to $125 \times 10^{-6} \mathrm{~m}$. The density tendency of studied systems as well as mechanical and the $B-H$ characteristic for $50 \mathrm{~Hz}$ supply frequency are shown in Table.

According to Table, the additional processing - annealing - influences the density that is lower than for the pressed systems. This is a well-known problem connected

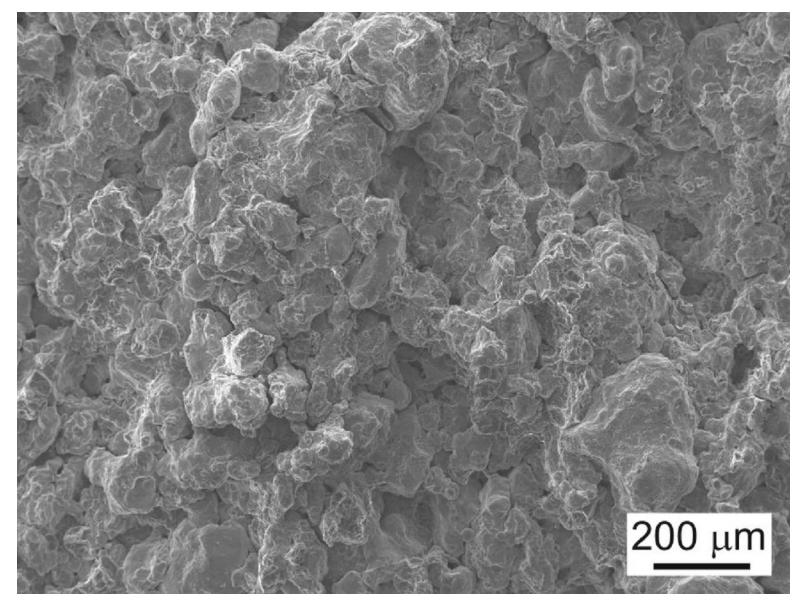

Fig. 1. Fracture surface of specimen pressed at $400 \mathrm{MPa}$ and heat treated. 


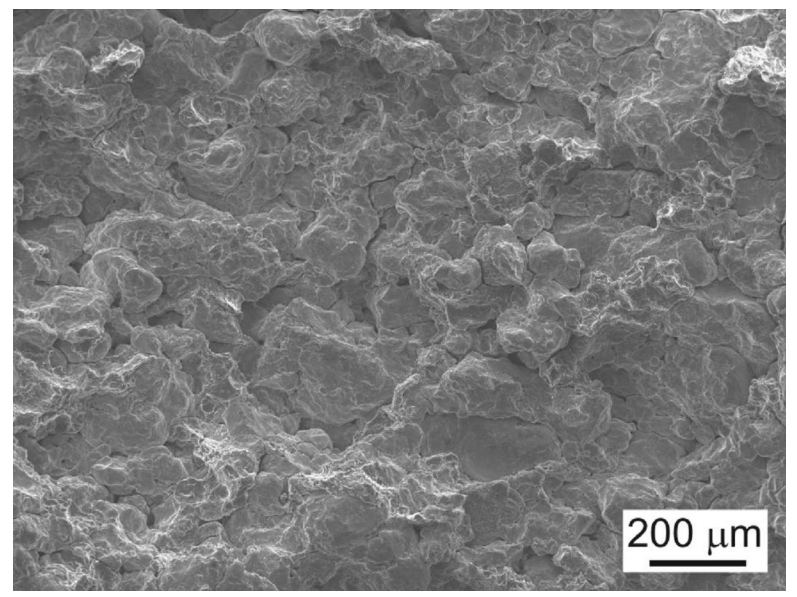

Fig. 2. Fracture surface of specimen pressed at $800 \mathrm{MPa}$ and heat treated.

to PM aluminium alloys sintering as well as sintering processing associated with wetting behaviour, swelling/ shrinkage and particle size distribution during heat treatment, mainly connected to vacuum atmosphere [7, 8].
In term of mechanical properties, the lower pressing pressure together with annealing shows value of bending strength close to $70 \mathrm{MPa}$. Application of higher pressure together with annealing leads to markedly decrease up to the value of about $30 \mathrm{MPa}$. In the pressed state, mainly the pores act as crack initiators and due to their presence the distribution of stress is inhomogeneous across the cross-section and leads to the reduction of the effective load bearing area. Heat treatment (annealing) supplement to diffusion and stress relaxation, therefore, reduces their size. Such a contrary behaviour in annealing state is still without a clear explanation and needs a deeper investigation. The typical fracture surfaces for investigated materials are presented in Figs. 1, 2.

It is considered that the broken particles can then fall into smaller spaces owing to their reduced sizes, and thus bring about a volume reduction. Size reduction by brittle fracture cannot continue indefinitely, and, ultimately, a transition to compaction by plastic deformation will occur as the pressure increases [9]. Compaction by brittle fracture is accompanied by an increase in the surface area of the compact with fragmentation of brittle porous aggregates of primary particles.

TABLE

Properties of investigated material. TRS $=$ transverse rupture strength

\begin{tabular}{c|c|c|c|c|c|c}
\hline \hline Pressure [MPa] & Density $\left[\mathrm{kg} / \mathrm{m}^{3}\right]$ & TRS [MPa] & Impact energy [J] & Iron losses [W/kg] & Remanence [T] & Coercivity [A/m] \\
\hline 400 & $6.42 \times 10^{3}$ & 68.22 & 0.60 & 14.5 & 0.007 & 194 \\
600 & $6.64 \times 10^{3}$ & 32.74 & 0.67 & 15.4 & 0.013 & 222 \\
800 & $6.77 \times 10^{3}$ & 29.35 & 0.76 & 25.3 & 0.023 & 310
\end{tabular}

\section{Conclusions}

1. In term of mechanical properties, the application of $400 \mathrm{MPa}$ pressure together with heat treatment condition shows value of bending strength near $70 \mathrm{MPa}$. The lower values of impact energy are confirmed by brittle fracture observed through fracture surfaces for both processing conditions.

2. From investigation of fracture surfaces it can be concluded that improvements in bonding during the pressing process and heat treatment can be helpful in the development of SMM to give a suitable combination among pressing pressure, annealing as well as magnetic properties.

\section{Acknowledgments}

J. Bidulská thanks the bilateral project SK-PL-0011-09.

This work was realized within the frame of the project "Technological preparation of electrotechnical steels with high permeability for electrodrives with higher efficiency" which is supported by the Operational Program "Research and Development" ITMS 26220220037, financed through European Regional Development Fund.

\section{References}

[1] S. Kikuchi, D. Koyama, K. Nakamura, in: Ultrasonics Symp., IEEE 2008, p. 2142, DOI 10.1109/ ULTSYM.2008.0530

[2] M. Actis Grande, A. Boglietti, A. Cavagnino, L. Ferraris, P. Ferraris, in: IECON, IEEE Industrial Electronics Society, Porto 2009, p. 1130.

[3] F.G. Hanejko, C. Oliver, H.G. Rutz, in: Advances in Powder Metallurgy and Particulate Materials, Vol. 6, MPIF, Princeton (NJ) 1992, p. 375.

[4] L. Hultman, O. Andersson, A. Jack, SAE Trans. 112, 158 (2003).

[5] I. Gilbert, S. Bull, T. Evans, A. Jack, D. Stephenson, A. de Sa, J. Mater. Sci. 39, 457 (2004).

[6] I. Gilbert, V. Moorthy, S.J. Bull, J.T. Evans, A.G. Jack, J. Magn. Magn. Mater. 242-245, 232 (2002).

[7] J. Bidulská, T. Kvačkaj, R. Kočiško, R. Bidulský, M. Actis Grande, Acta Metall. Slovaca 16, 4 (2010).

[8] H. Danninger, H.C. Neubing, J. Gradl, in: Powder Metallurgy'98, Vol. 5, EPMA, Shrewsbury 1998, p. 272 .

[9] P.J. Denny, Powder Technol. 127, 162 (2002). 